\title{
Wild to our marrow
}

Cite as: CMAJ 2019 September 30;191:E1083. doi: 10.1503/cmaj.190702

a $\mathrm{n}$ architecture of bone ...

a branching network of nerves flickering ... Inside the human body lies a realm ... each of us, wild to our marrow.

(Robert Moor, On Trails: An Exploration, Simon \& Schuster, 2016)

Lying cruciform on the exam table, she asks, "If you cut off my leg, will that stop the pain?" Her body destroying itself, diagnosis unknown. Oxycodone, Percocet, Fentanyl cannot help her now. Alone within an architecture of bone.

In the research lab, he measures reactions. Whether she feels heat or cold on her fingers. Is there sweat behind the knees? Can she feel pinpricks on the soles? She is unable to sit up without vomiting, a network of nerves flickering.

The human body, a realm still unknown, pathways branching like a deep-rooted elm, the gallows of Yggdrasil.

We navigate in darkness, systems collapse,

the body's chaotic ecology.

Who sees the fall of every sparrow?

Within each of us, a horde

of microorganisms burrow wild to our marrow.

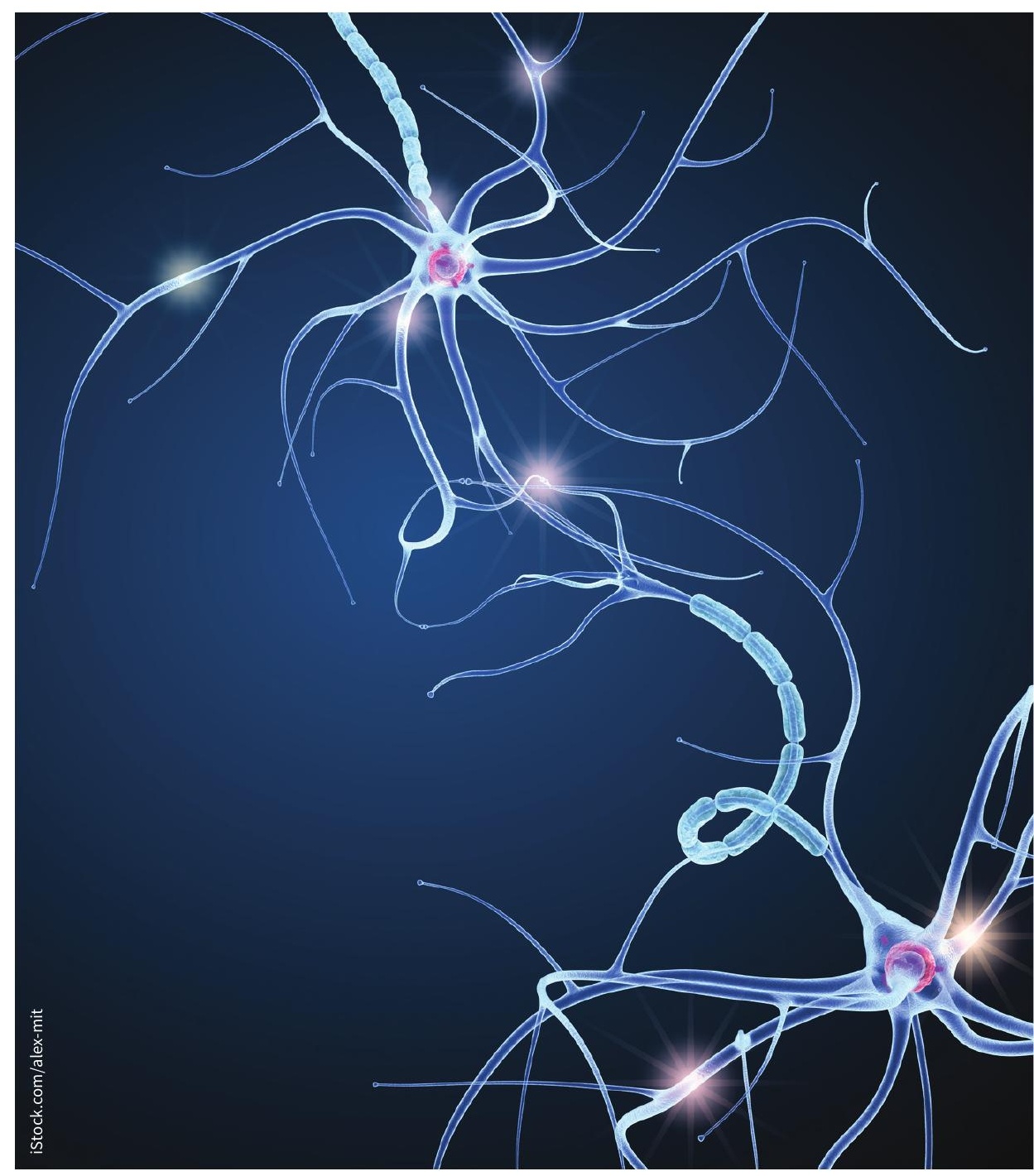

\section{Kat Cameron MA}

Edmonton, Alta.

This article has been peer reviewed. 